Vertebral fractures

\section{Clinical relevance of vertebral fractures}

\author{
W F Lems
}

Why are vertebral fractures so often overlooked?

O steoporotic fractures occur quite frequently: the lifetime fracture risk for a 50-year-old woman is $40 \% .^{1}$ Bone mineral density (BMD) is an important predictor of future fractures: the risk is increased twofold for each standard deviation (SD) decrease in $\mathrm{BMD}$, whereas the correlation between low BMD and fractures is strongest for measurements at the same site as that of the fracture. ${ }^{2}$ BMD is often measured for diagnosing osteoporosis ( $\mathrm{T}$ score $\leqslant-2.5$ $\mathrm{SD}$, according to the World Health Organization criteria), although these criteria were developed for epidemiological studies. However, the two-dimensional dual-energy $x$ ray absorptiometry images do not measure two other important properties of bone strength: the microarchitecture and its material composition. ${ }^{3}$

In a large meta-analysis, it has been shown that having a fracture is associated with an increased relative risk of subsequent fractures. ${ }^{4}$ In Maastricht, The Netherlands, a large study on 2419 patients aged $\geqslant 50$ years was performed: the absolute risk of developing a new clinical fracture within 2 years after a fracture was $>10 \% .^{5}$ In Glasgow, UK, a low BMD was found in $50-70 \%$ of the patients aged $\geqslant 50$ years with a clinical (nearly all non-vertebral) fracture. ${ }^{6}$ As effective osteoporosis drugs, particularly bisphosphonates, are nowadays available, ${ }^{7}$ awareness is growing that patients should be diagnosed and treated for osteoporosis in the case of a low BMD, particularly in combination with a clinical (non-vertebral) fracture.

The first reason for failing to diagnose vertebral fractures is its clinical presentation: non-vertebral fractures, for example, from the wrist or hip, are easy to diagnose in patients with severe pain and a deformity, usually after a fall. By contrast, diagnosing vertebral fractures is more complicated. They usually occur during daily activities, such as climbing stairs or bending forward, without a fall. The classic symptoms of vertebral fractures are back pain, limitation of spine mobility, height loss and disability. Back pain and difficulties in performing activities in daily life are predominantly observed in patients with lumbar or low-thoracic fractures, whereas mid-thoracic fractures may result in the reduction of pulmonary function and an increased risk of pulmonary infections. Vertebral fractures can be associated with severe pain, but can also be asymptomatic; one third of vertebral fractures correspond to a symptomatic period. $^{8}$

The second reason is that vertebral fractures are often overlooked in radiographs. In a study in which the results of local reports of radiographs were compared with a reference centre in $>2000$ patients from five continents, vertebral fractures were missed in $29-46 \%$ of them. ${ }^{9}$ The authors concluded that underdiagnosis of vertebral fractures was a global problem, probably related to lack of radiographic detection and the use of ambiguous terminology; they hence proposed the use of the term "fracture" consistently whenever radiographic deformities indicating fracture were identified. In a study of 934 hospitalised women aged $\geqslant 60$ years, chest radiographs were obtained for various reasons: moderate (25-40\% height loss) or severe ( $>40 \%$ height loss) vertebral fractures were scored in 132 (14\%) women by trained radiologists in a reference centre, but only 65 of 132 were reported in the $x$ ray report by the local radiologists, $23 \%$ in the medical report and $25 \%$ received treatment for osteoporosis. ${ }^{10}$ The percentage of patients with vertebral fractures would have been even higher if mild vertebral fractures had been counted and radiographs of the lumbar spine had also been available.

The third reason to miss the diagnosis of a vertebral fracture is that it can be overruled by another diagnosis with a bad prognosis-for example, a malignancy or dementia. The fourth reason for undetected vertebral fractures is related to missing the clinical relevance of diagnosing vertebral fractures.

So, how can we improve on this? Educational programmes are important in which radiologists and doctors are taught how to identify vertebral fractures and how to distinguish them from other abnormalities (trauma, degenerative diseases, ankylosing spondylitis, Scheuermann's disease or malignancy, etc). One excellent example is the "Vertebral Fracture Initiative", an educational programme from the International Osteoporosis Foundation (http://www. iofbonehealth.org).

\section{CLINICAL RELEVANCE OF VERTEBRAL FRACTURES}

It is important to realise that a prevalent vertebral fracture has a strong predictive value for future fractures, even after adjustment for age and BMD: in the Study of Osteoporotic Fractures, in which 9704 postmenopausal women were prospectively observed for 4 years, the risk of new vertebral fractures in patients with a prevalent vertebral deformity was increased fourfold, whereas the risk of hip fractures was doubled. ${ }^{11}$ The relative risk of future vertebral fractures (unadjusted for age and BMD) increased progressively in patients with severe vertebral fractures (from 3.0 in those with mild fractures to 12.7 in those with severe fractures) and in those with multiple vertebral fractures (from 3.1 in those with one fracture to 10.6 in those with $\geqslant 3$ vertebral fractures). The risk of a subsequent fracture is particularly high after an incident vertebral fracture: the risk of a subsequent vertebral fracture is $20 \%$ in the year after an initial vertebral fracture. $^{12}$

In the Study of Osteoporotic Fractures, the number of bed days and the number of days with back pain were counted. ${ }^{13}$ The patients were divided into three groups: those without incident vertebral fractures; those with vertebral fractures who did not come to clinical attention (asymptomatic vertebral fractures); and those with (symptomatic) vertebral fractures. Not surprisingly, in patients with symptomatic vertebral fractures, more days with back pain and with bedrest were found than in patients without vertebral fractures, but interestingly, also in those with asymptomatic vertebral fractures, the number of days in bed and the number with back pain were increased. Besides morbidity, vertebral fractures are also associated with an increased mortality: in an observational study over 14 years, the cumulative probability of death was nearly three times higher than normal in patients with a vertebral fracture, which was not changed after adjustment for age, sex, BMD or weight. ${ }^{14}$ However, on the basis of these data, it is not possible to discriminate whether the increased mortality is related to the vertebral fractures or to lifestyle factors and other concomitant diseases. 
In recent studies, it has been shown that some parameters of bone quality were abnormal in patients with vertebral fractures compared with people without a vertebral fracture, ${ }^{15}{ }^{16}$ which is intriguing, as no difference was found in age or bone volume, suggesting bone fragility in patients with vertebral fractures, irrespective of age and BMD. Oleksik et a ${ }^{15}$ found cortical thinning and loss of trabecular connectivity in patients with vertebral fractures, whereas in another histomorphometric study, the iliac cancellous density of osteocytes, which have a key role in the detection of microdamage, was $34 \%$ lower than that in controls. ${ }^{16}$

In the European Vertebral Osteoporosis Study, a population-based study of 15570 men and women aged 50-79 years in several European countries, in which all radiographs were analysed in one reference centre, the prevalence of vertebral fractures varied from $6 \%$ to $21 \% .{ }^{17}$ The prevalence of vertebral fractures was greater in younger men than in younger women, probably related to trauma. The prevalence increased with age in both sexes, although the gradient was steeper in women. ${ }^{17}$ In the European Prospective Osteoporosis Study, ${ }^{18}$ the incidence of vertebral fractures was observed over nearly 4 years in 3174 men (mean age 63 years) and 3614 women (mean age 62 years). The overall incidence (per year) of vertebral fractures was $12 / 1000$ in women and 7/1000 in men, indicating that the risk of incident vertebral fractures was (twofold) higher in older women than in older men. The incidence of vertebral fractures increased markedly with age-for example, in women from 6/ 1000 (aged 55-59 years) to 23/1000 (aged 75-79 years). In the Rotterdam Study, ${ }^{19}$ a large prospective population-based cohort study on men and women, low BMD and prevalent vertebral fractures were strong risk factors for incident vertebral fractures in men and women, whereas early menopause, current smoking and use of a walking aid were additional independent risk factors in women, and prevalent nonvertebral fractures in men.

For several osteoporosis drugs, particularly bisphosphonates, a reduction in vertebral and non-vertebral fractures in postmenopausal women was shown in randomised controlled trials on postmenopausal women, usually with one or more vertebral fractures at baseline. ${ }^{7}$

\section{VERTEBRAL FRACTURES IN PATIENTS WITH RHEUMATIC DISEASES}

High disease activity in patients with rheumatoid arthritis is associated with radiological joint damage and also with generalised bone loss ${ }^{20}$ and increased risk of fracture. ${ }^{21} 22$ In a preliminary proposal, it was advocated to measure BMD in women with rheumatoid arthritis fulfilling two of three of the following criteria: age $>60$ years, high disease activity and immobility. ${ }^{23}$ It has been suggested that both local and generalised bone loss in patients with rheumatoid arthritis are related to the same mechanism, in which the ratio between receptor activator of nuclear factor kappa B/osteoprotegerin is increased, leading to an upregulation of osteoclast activity both locally and throughout the skeleton. ${ }^{24}$ In line with this suggestion, it was shown that the Larsen score, a cumulative measure of disease activity, was a determinant of both low BMD and vertebral deformities. ${ }^{25}$ In a cohort study in Norway, the prevalence of vertebral fractures in women with rheumatoid arthritis was compared with that in controls: vertebral fractures were scored in $17.3 \%$ of patients versus $10 \%$ of controls (odds ratio 2.0, 95\% confidence interval 1.1 to 3.7$)$. $^{22}$

It is a challenge for rheumatologists to detect vertebral fractures in their patients with rheumatoid arthritis. The combination of data from population-based studies in which a prevalence of vertebral fractures in people aged $>50$ years was found to be between $6 \%$ and $21 \%{ }^{17}$ with data on rheumatoid arthritis in which a twofold increased relative risk for vertebral fractures was found ${ }^{21}$ suggests that an appreciable proportion of patients with rheumatoid arthritis have vertebral fractures. The same seems to be true in other rheumatic diseases-for example, in systemic lupus erythematosus (SLE): in a cross-sectional study in 107 patients with SLE, the prevalence of vertebral fractures was $20 \%$, which is remarkable, as the mean age of these patients with SLE was only 41 years. ${ }^{26}$ In ankylosing spondylitis, the relative risk of vertebral fractures was increased sevenfold, whereas no difference was found for non-vertebral fractures. ${ }^{27}$ The use of glucocorticoids was also related to fractures: the prevalence of vertebral fractures was high in postmenopausal women with longstanding rheumatoid arthritis (58\%) treated with glucocorticoids ${ }^{28}$.

Apart from the four reasons described above as to why vertebral fractures are so often missed in the general population, the risk of underdiagnosis of vertebral fractures might be even higher in patients with rheumatic diseases (box 1): the prevalence of vertebral fractures is higher than in the general population-at least partly related to the use of glucocorticoids-and doctors might not think of vertebral fractures because of the young age of the patients or because back pain is also described for ankylosing spondylitis.
Box 1 Why are vertebral

fractures so often missed?

- Diagnosing a vertebral fracture is more difficult than diagnosing a non-vertebral fracture

- Vertebral fractures are often overlooked in radiographs

- The diagnosis of a vertebral fracture can be overruled by another diagnosis

- Missing the clinical relevance of diagnosing vertebral fractures

- NB, in patients with rheumatic disease, the risk of undetected vertebral fractures is even higher: the prevalence of vertebral fractures is higher than that in the general population, at least partly related to the use of glucocorticoids, and doctors might not think of vertebral fractures - for example, because of the young age of the patient or because back pain is also described for ankylosing spondylitis.

\section{WHO SHOULD UNDERGO RADIOGRAPHY OF THE SPINAL CORD?}

In this issue of the Annals, Roux et al ${ }^{29}$ (see $p$ 81) describe a clinical tool for the indication of $x$ rays of the spinal cord in postmenopausal women with osteoporosis, presenting with back pain. I completely agree with the authors that vertebral fractures are often underdiagnosed, and I support them bringing up a relevant question: how to detect vertebral fractures? In a group of 410 postmenopausal women with osteoporosis, they found that $>50 \%$ of them had at least one vertebral fracture. The high prevalence of vertebral fractures is probably related to their inclusion criteria: older women (mean age 75 years) whose BMD was in the osteoporotic range. The question is whether it is useful to order radiography of the spine in these patients if they present with back pain. The authors describe a model including six parameters, which can be used for the prediction of vertebral fractures. As expected, the risk of a vertebral fracture was higher in elderly patients, in patients with severe height loss, and in those with the sudden occurrence of severe back pain. However, the proposed algorithm can help in diagnosing an incident fracture only when an earlier radiograph of the spinal cord is available, and the consequences of diagnosing a vertebral fracture in a patient 
with a BMD in the osteoporotic range are not fully clear. It is even more challenging to develop an algorithm to detect vertebral fractures in patients in whom osteoporosis is not diagnosed.

\section{SUMMARY}

Vertebral fractures are common in elderly people, and may be associated with back pain, height loss, days of bed rest and disability. Vertebral fractures are often missed for several reasons. Bone quality in patients with a vertebral fracture seems to be inferior, and prevalent vertebral fractures are strong predictors for new vertebral and non-vertebral fractures. Effective osteoporosis drugs, particularly bisphosphonates, are available: it is remarkable that the evidence for reduction in vertebral and non-vertebral fractures has been dominated by studies in which patients with $\geqslant 1$ vertebral fractures were enrolled.

Although scarce, the available data suggest an increased relative risk of vertebral fractures in patients with systemic rheumatic diseases, indicating that the detection of vertebral fractures is a challenge, both for clinicians treating patients with rheumatic diseases and for those conducting research on osteoporosis in rheumatic diseases.

Ann Rheum Dis 2007;66:2-4. doi: 10.1136/ard.2006.058313

\section{Author's affiliations}

W F Lems, Vrije Universiteit Medical Centre; Slotervaart Hospital; Jan van Breemen Institute, Amsterdam, The Netherlands

Correspondence to: Dr W F Lems, Department of Rheumatology 4A42, Vrije Universiteit Medical Centre, Postbox 7057, 1007 MB Amsterdam,

The Netherlands; wf.lems@vumc.nl

See linked article, p 81

Accepted 7 October 2006

\section{REFERENCES}

1 Melton U III, Chrishilles EA, Cooper C, Lane AW Riggs BL. Perspective how many women have osteoporosis? J Bone Miner Res 1992;7:1005-10.

2 Marshall D, Johnell O, Wedel H. Meta-analysis of how well bone mineral density predicts occurrence of osteoporotic fractures. BM 1996;312:1254-9.

3 Seeman E, Delmas PD. Bone quality-the material and structural basis of bone strength and fragility. N Engl J Med 2006;354:2250-61.

4 Klotzbuecher CM, Ross PD, Landsman PD, Abbott TA, Berger M. Patients with prior fractures have an increased risk for future fractures: a summary of the literature and statistical synthesis. J Bone Miner Res 2000;15:721-39.

5 van Helden S, Cals J, Kessels F, Brink P, Dinant GJ Geusens P. Risk of new clinical fractures within two years following a fracture. Osteoporosis Int 2006;17:348-54.

6 Mc Lellan AR, Gallacher SJ, Fraser M, McQuillian $C$. The fracture liaison service: success of a program for the evaluation and management of patients with osteoporotic fracture. Osteoporosis Int 2003; 14:1028-34.

7 Cranney A, Guyatt G, Griffith L, Wells G, Tugwell P Rosen C. Summary of meta-analysis of therapies for postmenopausal osteoporosis. Endocr Rev 2002;23:570-8.

8 Cooper C, Atkinson EJ, O'Fallon M, Melton U III. Incidence of clinically diagnosed vertebral fractures: a population based study in Rochester, Minnesota. J Bone Miner Res 1992;7:221-7.

9 Delmas PD, van de Langerijt L, Watts NB, Eastell $R$ Genant H, Graver A, et al. Underdiagnosis of VFs is a worldwide problem: the IMPACT study. J Bone Miner Res 2005;20:557-63.

10 Gehlbach SH, Bigelow C, Heimisdottir M, May S, Walker M, Kirkwood JR. Recognition of VF in a clinical setting. Osteoporosis Int 2000;1 1:577-82.

11 Black DM, Arden NK, Palermo L, Pearson J, Cummings SR. Prevalent vertebral deformities predict hip fractures and new vertebral deformities but not wrist fractures. J Bone Miner Res 1999; 14:821-8.

12 Lindsay R, Silverman SL, Cooper C, Hanley DA Barton I, Broy SB, et al. Risk of new vertebral fracture in the year following a fracture. JAMA 2001;285:320-3.

13 Nevitt MC, Ettinger B, Black DM, Stone K, Jamal SA, Ensrud K, et al. The association of radiographically detected vertebral fractures with back pain and function: a prospective study. Ann Intern Med 1998; 128:793-800.

14 Pongchaiyakul C, Nguyen ND, Jones G, Center JR Eisman JA, Nguyen TV. Asymptomatic vertebral deformity as a major risk factor for subsequent fractures and mortality: a longterm prospective study. J Bone Miner Res 2005;20:1349-55.

15 Oleksik A, OH S, Vedi S, Bravenboer N, Compston J, Lips P. Bone structure in patients with low bone mineral density with or without vertebral fractures. J Bone Miner Res 2000;15:1368-75.

16 Qui S, Rao D, Palnitkar S, Parfitt AM. Reduced iliac cancellous osteocyte density in patients with osteoporotic vertebral fracture. J Bone Miner Res 2003; 18: 1657-63.

17 O'Neill TW, Felsenberg D, Varlow J, Cooper C, Kanis JA, Silman AJ. The prevalence of vertebral deformity in European men and women: the European Vertebral Osteoporosis Study. J Bone Miner Res 1996;11:1010-18.

18 Felsenberg D, Silman AJ, Lunt $M$, Armbrecht $G$, Ismail AA, Finn JD, et al. Incidence of vertebral fractures in Europe: results from the European Prospective Osteoporosis Study. J Bone Miner Res 2002; 17:716-24.

19 van der Klift M, de Laet CEDH, Mc Closkey EV Johnell O, Kanis JA, Hofman A. Risk factors for incident vertebral fractures in men and women: the Rotterdam Study. J Bone Miner Res 2004;19:1172-80.

20 Gough AK, Lilley J, Eyre S, Holder RL, Emery P. Generalised bone loss in patients with rheumatoid arthritis. Lancet 1994;344:23-7.

21 Huusko TM, Korpela M, Parppi P, Avikainen V, Kautiainen H, Sulkava R. Threefold increase of hip fractures with rheumatoid arthritis in Central Finland. Ann Rheum Dis 2001;60:521-2.

22 Orstavik RE, Haugeberg G, Mowinckel P, Hoiseth A, Uhlig T, Falch JA. Vertebral deformities in rheumatoid arthritis: a comparison with population based controls. Arch Intern Med 2004; 164:420-5.

23 Lems WF, Dijkmans BA. Should we look for osteoporosis in patients with rheumatoid arthritis? Ann Rheum Dis 1998;57:325-7.

24 Sambrook PN. The skeleton in rheumatoid arthritis: common mechanisms for bone erosions and osteoporosis? J Rheumatol 2000;27:2541-2.

25 Lodder MC, Haugeberg G, Lems WF, Uhlig T, Orstavik RE, Kostense PJ, et al. Radiographic damage associated with low bone mineral density and vertebral deformities in rheumatoid arthritis: the Oslo-Truro-Amsterdam (OSTRA) collaborative study. Arthritis Rheum 2003;49:209-15.

26 Bultink IE, Lems WF, Kostense PJ, Dijkmans BA, Voskuyl AE. Prevalence of and risk factors for low bone mineral density and vertebral fractures in patients with systemic lupus erythematosus. Arthritis Rheum 2005;52:2044-50.

27 Cooper C, Carbone L, Michet CJ, Atkinson EJ, O'Fallon WM, Melton $\amalg$ III. Fracture risk in patients with ankylosing spondylitis: a population based study. J Rheumatol 1994;21:1877-82.

28 Lems WF, Jahangier ZN, Jacobs JWJ, Biilsma JWJ. Vertebral fractures in patients with rheumatoid arthritis treated with corticosteroids. Clin Exp Rheumatol 1995;13:293-7.

29 Roux C, Priol G, Fechtenbaum J, Cortet B, LiuLeage $S$, Audran $M$, et al. A clinical tool for the indication of spine $\mathrm{X}$-rays in postmenopausal women with osteoporosis with back pain. Ann Rheum Dis 2007;66:81-5. 